\title{
Perspectives on electronic medical records adoption: electronic medical records (EMR) in outcomes research
}

This article was published in the following Dove Press journal:

Patient Related Outcome Measures

29 April 2010

Number of times this article has been viewed

\author{
Dan Belletti' \\ Christopher Zacker' \\ C Daniel Mullins² \\ 'Novartis Pharmaceuticals \\ Corporation, East Hanover, NJ, USA; \\ 2University of Maryland School \\ of Pharmacy, Baltimore, MD, USA
}

\begin{abstract}
Health information technology (HIT) is engineered to promote improved quality and efficiency of care, and reduce medical errors. Healthcare organizations have made significant investments in HIT tools and the electronic medical record (EMR) is a major technological advance. The Department of Veterans Affairs was one of the first large healthcare systems to fully implement EMR. The Veterans Health Information System and Technology Architecture (VistA) began by providing an interface to review and update a patient's medical record with its computerized patient record system. However, since the implementation of the VistA system there has not been an overall substantial adoption of EMR in the ambulatory or inpatient setting. In fact, only $23.9 \%$ of physicians were using EMRs in their office-based practices in 2005 . A sample from the American Medical Association revealed that EMRs were available in an office setting to $17 \%$ of physicians in late 2007 and early 2008 . Of these, $17 \%$ of physicians with EMR, only $4 \%$ were considered to be fully functional EMR systems. With the exception of some large aggregate EMR databases the slow adoption of EMR has limited its use in outcomes research. This paper reviews the literature and presents the current status of and forces influencing the adoption of EMR in the office-based practice, and identifies the benefits, limitations, and overall value of EMR in the conduct of outcomes research in the US.
\end{abstract}

Keywords: electronic medical records, health information technology, medical errors

\section{Introduction}

Health information technology (HIT) is engineered to promote improved quality and efficiency of care, and reduce medical errors. Healthcare organizations have made a significant investment in HIT tools in recent years. ${ }^{1}$ One such technological advance is the electronic medical record (EMR), defined as personal data recorded, developed, maintained and/or provided by clinicians and providers in direct patient care. ${ }^{2}$ The Department of Veterans Affairs, a leader in EMR adoption, was one of the first large healthcare systems to fully implement EMR technology in 1997. The Veterans Health Information System and Technology Architecture (VistA) began by providing an interface to review and update a patient's medical record with its computerized patient record system. This system was eventually fully integrated to allow for ordering medications, special procedures, X-rays, patient care nursing orders, special diets, and laboratory tests. ${ }^{3}$

However, since the implementation of the VistA system there has not been an overall substantial adoption of EMRs in the ambulatory or inpatient setting. According to a sample of ambulatory care physicians in the National Ambulatory Medicare Care Survey, only $23.9 \%$ of physicians were using EMRs in their office-based
Correspondence: Dan Belletti

Assistant Director Evidence Based

Medicine, Regional Outcomes Research,

Novartis Pharmaceuticals Corporation,

East Hanover, NJ, USA

Tel + | 6I0-760-I35I; Cell 973-975-6522

Fax +1 4I0-702-45I0

Email Dan.belletti@novartis.com 
practices in 2005. ${ }^{4} \mathrm{~A}$ sample of the Physician Masterfile of the American Medical Association, which excludes D.O. (osteopathic doctors) revealed that EMR were available in an office setting to $17 \%$ of physicians in late 2007 and early $2008 .{ }^{5}$ Out of these, $17 \%$ of physicians with EMR, only $4 \%$ were considered to be fully functional EMR systems encompassing the following four domains: 1) recording patients' clinical and demographic data; 2) viewing and managing results of laboratory tests and imaging; 3 ) managing order entry; and 4) supporting clinical decisions. ${ }^{5}$ With the exception of some large aggregate EMR databases (General Electric, eg, with over 5 million de-identified care records), the slow adoption of EMR has limited its use in outcomes research. ${ }^{6}$

\section{Objective}

This paper reviews the literature and presents the current status of and forces influencing the adoption of EMR in the office-based practice in the US, and identifies the benefits, limitations, and overall value of EMR in the conduct of outcomes research.

\section{Description}

\section{Current forces facilitating EMR adoption}

Despite slow adoption, several forces are driving physicians towards EMR implementation, including the US government and professional healthcare organizations. In the 2004 Technology Agenda Promoting Innovation and Competitiveness, President Bush called for most Americans to have access to an interoperable electronic health record by $2014,{ }^{7}$ with "interoperable" defined as the ability to exchange clinical patient data between providers and systems to achieve continuity of care and to enable use of the data once it has been exchanged. ${ }^{8}$ Congressional bills S.1418 and H.R. 4726, the Wired for Health Care Quality Act and H.R. 4157, the Health Information Technology Promotion Act of 2005, furthered the cause of health information technology and EMR. The Wired for Health Care Quality Act established a nationwide health information technology infrastructure including uniform standards and provided legislative authorization for the Office of the National Coordinator of Health Information Technology. The Health Information Technology Promotion Act of 2005 provided legislative authorization for the Office of the National Coordinator and charged it with overseeing a strategic plan for national health information technology, along with providing a series of grants for integrated health systems and small physician practices to improve care through use of health information technology. ${ }^{9}$ In an effort to standardize EMR technology, the Certification Commission for Healthcare Information Technology (CCHIT) certified ${ }^{a}$ 58 ambulatory or clinician-based electronic health record products in 2007 providing the first standardization and quality metrics for EMR technology. ${ }^{10}$ Nationwide programs for healthcare quality improvement have chosen to implement CCHIT certified electronic health records as sufficient qualification to exhibit the use of electronic information at levels that compensate physicians with monetary bonuses as a reward for superior management of patients with chronic ailments. ${ }^{11}$ Finally, the American Recovery and Reinvestment Act of 2009 includes US $\$ 19$ billion in incentives for health providers to switch electronic health records to EMRs. ${ }^{12,13}$

Several nonprofit and professional organizations, including the American Medical Association (AMA), are also pushing for the greater adoption of EMR to foster improved treatment, public health, patient safety, quality improvement, medical liability defense, and research. ${ }^{14}$ The Institute of Medicine advocates the use of EMR for improved quality of care including reduced lag time allowing for quicker recognition and treatment of medical problems and improved workflow processes by eliminating lost orders and illegible orders with electronic order entry management. ${ }^{15}$ The Agency for Healthcare Research and Quality (AHRQ) reports that the use of EMRs supports a higher standard of care consistent across the country. For example, through the use of EMRs physicians and agencies have been able to track diabetes populations in the aggregate. ${ }^{16}$

Increasingly physicians are receiving various incentives to hasten EMR adoption. In spring of 2008 the Centers for Medicare and Medicaid Services (CMS) began a demonstration project, including participation by up to 1200 physician practices, to evaluate the benefit of EMR on 1) adverse drug events, medical errors, and redundant tests; 2) ease of diagnosis of various serious illnesses and greater use of preventative services; 3 ) organization of patient treatment history, making it easier to find vital health information and prescribed treatment; and 4) communication between patients and providers, giving patients better access to timely information. ${ }^{7}$ The program provides financial incentives to physician groups using certified electronic health records (EHR) to meet clinical quality measures. ${ }^{7}$

Some insurers are also offering discounts on malpractice insurance for physicians who utilize EMR systems. A survey conducted by the Medical Records Institute and Professional Risk Associates from March to June 2007 showed that nearly

${ }^{\mathrm{a}}$ Certification, pre-marketing certification, or extension of certification. 
$20 \%$ of physician responders received a discount on their malpractice insurance for having an EMR system. ${ }^{17}$ Additionally, many health plan pay-for-performance programs now include EMR. For example, as part of its pay-for-performance quality goals, Partners Healthcare, an integrated health system in Boston, has successfully driven EMR adoption from 9\% of primary care physicians in 2003 to an estimated $90 \%$ at the end of 2007. ${ }^{18}$ In a recent article in Morbidity and Mortality Weekly Report, it was noted that "... automated, active surveillance using EMR data has the potential to improve public health monitoring by ensuring that cases are reported and by enhancing the timeliness, accuracy and clinical detail of reports." ${ }^{19 \mathrm{~b}}$

Despite support for EMR adoption, barriers still exist including high costs, lack of certification and standardization and interoperability, concerns about privacy, disruptive effects on practices, and a disconnect between who pays for and who profits from EMR systems. ${ }^{18}$ Limited incentives, large upfront costs, and decreased revenue during initial implementation (and possibly ongoing) are key financial barriers to adoption. ${ }^{20,21}$

\section{Evaluation}

\section{Potential scope of EMR in outcomes research}

One opportunity or benefit often overlooked in any EMR adoption decision is the use of EMR data in outcomes research. Identified as an urgent need in the 1980s, outcomes research seeks to measure the end results of particular healthcare practices, interventions, products, and healthcare technologies. ${ }^{22}$ In order to conduct the most robust outcomes measurement, access to a fully integrated system with both clinical and healthcare utilization data would be desired. Although an EMR system may not have all the necessary components independently, a properly built system could allow integration with other electronic data, including medical and pharmacy claims data and even patient survey input. Data from EMR represent just one segment of a larger realworld data source (including EMR, claims data, and process measures), and is supplemental to clinical trial data. However, EMR access to real-world clinical measures, with near realtime acquisition and retrieval, is paramount to the conduct of robust outcomes research.

\footnotetext{
'In a recent article in the Boston Globe, John Halamka noted that in surveying "all the zip code of Greater Boston," one finds that the penetration of EHRs that are live and in production is 76\% - that's compared with just $12 \%$ nationally. Halamka, Bates spotlight health IT use in Boston, February 10, 2010.
}

Historically, outcomes researchers have relied on retrospective data including medical charts and claims databases, or primary data collection (eg, patient surveys and clinical trials) as their main source of data. However, individually each of these data sources has inherent limitations. For example, administrative claims databases, whether medical or pharmacy, include data only on patients for whom a claim was paid and have limited or no clinical information such as blood pressure measures (Table 1). Outcomes studies that rely on claims data also have inherent sample selection issues in that they only enable evaluation of patients who filled at least one claim and may represent a sicker or possibly more motivated population (use by users). To obtain outcomes data on clinical measures such as blood pressure, cholesterol levels, and body mass index, researchers must often resort to the laborious task of abstracting patients' paper medical charts, a task with numerous drawbacks. Such manual reviews are time and resources intensive, limiting the total sample size and threatening the power necessary to detect a statistical difference.

The use of EMR data has the potential to not only address these inherent data challenges, but also expand the opportunities for outcomes research. With the large sample sizes and comprehensiveness of EMR data, it becomes feasible to electronically link EMR data with medical and pharmacy claims data to conduct pharmaco-vigilence and real-world effectiveness studies, and possibly even comparative effectiveness evaluations. With more than 3 billion prescriptions written per year, prescribing is one of the largest, paper-based processes in the US. Not surprisingly, it is also one of the most inefficient. In a recent report to Congress, the CMS reported approximately a third of all prescriptions generating a callback from a pharmacy and physicians and their staff spend hours each week pulling charts and verifying information. ${ }^{23}$ EMRs can help clinicians increase patient safety, reduce pharmacy callbacks, and improve office efficiency. ${ }^{7}$

EMR clinical data allow cross-payer analysis and, by linking EMR data with these claims data, economic analyses becomes more robust, patients' actual behaviors (eg, medication compliance) can be tracked to clinical outcomes and cost of care, and outcomes researchers are no longer constrained to studying only "use by users". EMR contains longitudinal data which can be used to track the diffusion of new clinical evidence and innovations and their related impact on outcomes.

Prospective studies may also utilize the real-time flexibility of EMR systems to capture study specific data elements which are integrated into the total patient record. To communicate better clinical outcomes, one needs to understand the 
Table I Comparison of data sources for outcomes research

\begin{tabular}{|c|c|c|}
\hline Data source & Benefits & Challenges \\
\hline $\begin{array}{l}\text { Electronic medical records } \\
\text { (EMRs) }\end{array}$ & $\begin{array}{l}\text { Data available to reflect entire care experience; data } \\
\text { can be analyzed in an ongoing and real-time basis for } \\
\text { entire populations under care; may improve depth and } \\
\text { breadth of outcomes studies; used with e-prescribing } \\
\text { can reduce adverse drug events, medical errors and } \\
\text { redundant tests }\end{array}$ & $\begin{array}{l}\text { Converting paper-based systems to electronic; } \\
\text { collecting and storing data in a standardized format; } \\
\text { Certification to ensure security and privacy of EMR } \\
\text { systems; interoperability; slow adoption }\end{array}$ \\
\hline Paper records & $\begin{array}{l}\text { Captures clinical characteristics and prescribing } \\
\text { patterns }\end{array}$ & $\begin{array}{l}\text { Accessing and use of data requires significant time } \\
\text { commitment; difficult to merge with claims data; } \\
\text { increased chance for missing/incomplete data; limits } \\
\text { sample sizes; costly to extract data }\end{array}$ \\
\hline Medical and pharmacy claims & $\begin{array}{l}\text { Captures real-world utilization patterns; encompass a } \\
\text { wealth of variables and analyses of these data can be } \\
\text { used for benchmarking purposes }\end{array}$ & $\begin{array}{l}\text { Lag time in the availability of information about } \\
\text { new therapies; does not capture clinical experience; } \\
\text { data limited to patients with adjudicated claims }\end{array}$ \\
\hline Primary data collection & $\begin{array}{l}\text { Ability to structure assessment to capture variables of } \\
\text { interest; ability to measure variables or characteristics } \\
\text { that may not be contained in a medical chart or } \\
\text { claims database }\end{array}$ & $\begin{array}{l}\text { Difficulty with patient recruitment; time and } \\
\text { resources intensive to collect and analyze data }\end{array}$ \\
\hline
\end{tabular}

multifaceted interactions of everyday clinical choices made by thousands of clinicians and millions of patients. Research utilizing EMR data can also help identify the combination of real-world clinical evidence, tools embedded in the EMR (decision support), and patient information to produce better, safer outcomes for patients. ${ }^{24}$

\section{Value of EMR in outcomes research}

Once the barriers to adoption are surmounted, the time benefit, resource benefit, and ability to overcome missing or incomplete data with EMR will change the landscape of outcomes research studies. Quicker, more efficient and potentially more accurate data collection and larger sample sizes, in comparison with paper medical charts, can provide an advantage to the performance of more robust outcomes studies generating evidence over time, at significantly decreased costs. In addition to improving the quality of care and integrating healthcare networks, EMRs can assist in identifying adverse events and providing techniques and strategies to address them when they occur. ${ }^{25}$

One such domain in which EMR has successfully been used is quality improvement, including the use of clinical data to assess, facilitate and develop evidence based practice guidelines. A successful quality improvement study often requires medical record data to capture important clinical variables related to the disease condition of interest. The use of EMRs have been utilized and validated across therapeutic areas. Chronic disease management researchers have identified information and communication technology, such as the EMR systems, as a key dimension of success in a comprehensive quality improvement framework for knowledge translation. ${ }^{26}$ Psychiatrists have applied these EMR methods to efficiently monitor antipsychotic prescribing for quality improvement. ${ }^{27}$ In the field of cardiology, a 31-physician group seeing 40,000 patients per year reported that the use of EMRs provided a single, uniform medical record; gave them the ability to access all medical records from all practice locations; improved documentation and coding; cut transcription costs; and improved research overall. ${ }^{28}$ Additionally, Benin et al conducted a study of the adherence to guidelines for diagnostic testing and antibiotic use for pharyngitis. ${ }^{29}$ Without EMR in these studies, the breadth of data collected would have been severely limited.

EMR can facilitate accurate assessment of the proportion of patients with diabetes or hypertension in whom hemoglobin $\mathrm{A}_{1 \mathrm{C}}\left(\mathrm{HbA}_{1 \mathrm{C}}\right)$ or blood pressure is not controlled. A physician, medical director or quality director could review the EMR database, identify all patients with diabetes with an $\mathrm{HbA}_{1 \mathrm{C}}$ greater than $7 \%$ and intervene on those not attaining recommended $\mathrm{HbA}_{1 \mathrm{C}}$ levels. This approach represents a quick, less expensive, and more comprehensive (compared to reviewing medical charts) method to conduct outcomes research for quality or performance improvement. ${ }^{30}$ Some physicians believe that EMRs have a significant value for research that is relevant to family medicine and useful for patient care; beyond that, the data in EMRs can certainly contribute information within the health care system more effectively and efficiently. ${ }^{31}$ The ability to perform practice based 'research' in the form of quality improvement lends itself to improving the timeliness 
of continuous process improvement, that is, changing processes within the practice (even within the EMR system itself), using the system to track these changes and report on the effects - in real time.

Similar to quality improvement, several studies have been published that used EMR data to measure retrospectively outcomes for oncology, anemia disorders, infectious disease, rheumatology, and other highly specialized areas that require detailed clinical data to measure outcomes appropriately. One such example was the use of EMR to assess Medicare's National Drug Coverage Determination (NCD) on the use of erythropoiesis-stimulating agents (ESA). No other data source, other than EMR, was available to capture administration patterns, clinical lab values, and transfusion rates. Additionally, the outcomes needed were time sensitive and medical chart review would not have provided data in a timely manner. A study conducted within a large oncology practice provided timely evidence suggesting that the NCD led to increased blood transfusions in Medicare chemotherapy-induced cancer patients. ${ }^{32}$ This study could not have been conducted if EMR technology were not available. EMR systems to support HIV treatment date back 10 years to Safran et al who developed an ambulatory medical record component of the information system at Beth Israel hospital in Boston that included email malerts for doctors about patients with low CD4 counts. This system/process demonstrated an improved quality of care. ${ }^{33}$

Beyond quality improvement and retrospective studies, EMR in outcomes research is sparse (Table 2). It is important to recognize the use and principal implications of EMR to outcomes research in areas such as patient-reported outcomes studies, an opportunity virtually unexplored. EMR offers the clinician and researcher easier implementation of skip patterns, avoidance of secondary data entry errors, as well as the ability to quickly assess patient thoughts and perceptions regarding therapy or a particular intervention at the point of

Table 2 Outcomes research using electronic medical reporting

\begin{tabular}{|c|c|c|c|c|}
\hline $\begin{array}{l}\text { Outcomes research } \\
\text { examples }\end{array}$ & $\begin{array}{l}\text { Limitations to using } \\
\text { paper chart }\end{array}$ & $\begin{array}{l}\text { Available } \\
\text { evidence }\end{array}$ & $\begin{array}{l}\text { Examples of published } \\
\text { evidence using EMR }\end{array}$ & $\begin{array}{l}\text { Advantages of using } \\
\text { EMR vs paper chart }\end{array}$ \\
\hline $\begin{array}{l}\text { Quality improvement/disease } \\
\text { management }\end{array}$ & $\begin{array}{l}\text { Costly to collect data on all } \\
\text { patients, thus randomization } \\
\text { of study patients is required }\end{array}$ & Moderate & $\begin{array}{l}\text { Benin }^{29} \text { Miller }^{42} \text { Baron }^{43} \\
\text { Crosson }^{44} \text { Ornstein }^{45} \text { Henry }^{46}\end{array}$ & $\begin{array}{l}\text { May assess all patients vs } \\
\text { randomized subset; may } \\
\text { incorporate interventions } \\
\text { within EMR system; may } \\
\text { link to billing claims }\end{array}$ \\
\hline $\begin{array}{l}\text { Retrospective studies (eg, compliance, } \\
\text { persistence, drug utilization) }\end{array}$ & $\begin{array}{l}\text { Only captures data from } \\
\text { restricted population }\end{array}$ & Limited & Shah $^{53}$ Garg $^{54}$ Eddy $^{30}$ & $\begin{array}{l}\text { Ability to capture services } \\
\text { from several payers; } \\
\text { increased efficiency; } \\
\text { detailed data }\end{array}$ \\
\hline Patient-reported outcomes & $\begin{array}{l}\text { Requires separate survey/ } \\
\text { questionnaire }\end{array}$ & Limited & $\begin{array}{l}\text { Wuerdeman }{ }^{47} \text { Stewart }^{35} \\
\text { Staroselsky }{ }^{48} \text { Staroselsky }{ }^{49}\end{array}$ & $\begin{array}{l}\text { Ability for patient to enter } \\
\text { data themselves; up-to } \\
\text { date information; ability to } \\
\text { capture services provided } \\
\text { outside of practice }\end{array}$ \\
\hline $\begin{array}{l}\text { Economic modeling (eg, cost benefit, } \\
\text { cost effectiveness) }\end{array}$ & $\begin{array}{l}\text { Data collection time; } \\
\text { limited patient population } \\
\text { generalized to broader } \\
\text { population }\end{array}$ & Limited & $E_{d d y}{ }^{30}$ & $\begin{array}{l}\text { Increased efficiency; } \\
\text { increased patient popula- } \\
\text { tion size; ability to link } \\
\text { cost data from claims } \\
\text { database to utilization } \\
\text { variables }\end{array}$ \\
\hline Prospective studies & $\begin{array}{l}\text { Chart abstraction to } \\
\text { identify patients for inclu- } \\
\text { sion; time intensive }\end{array}$ & Limited & Pakhomov $^{50}$ Diero $^{51}$ & $\begin{array}{l}\text { Easier identification of } \\
\text { patients for inclusion; } \\
\text { more accurate informa- } \\
\text { tion; reminders built into } \\
\text { protocol }\end{array}$ \\
\hline Comparative effectiveness & $\begin{array}{l}\text { Missing or incomplete } \\
\text { data; time intensive data } \\
\text { collection }\end{array}$ & Limited & Pace $^{55}$ Chaudhry ${ }^{56}$ & $\begin{array}{l}\text { Increased efficiency; } \\
\text { increased clinical details } \\
\text { to adjust for confounding } \\
\text { variables }\end{array}$ \\
\hline
\end{tabular}

${ }^{\mathrm{a}}$ Does not include posters presented at various conferences. 
care. ${ }^{34}$ One such attempt by Stewart et al took questionnaire data from a pediatric neurodevelopmental clinic and digitized and imported the data into EMR templates. Access to structured patient and physician data was used to generate highly tailored after-visit summaries, including education material. ${ }^{35}$ Although probably not the primary objective of this particular study, much more potential was available to measure patient reported outcomes by integrating patient questionnaires and survey data into the EMR system. Integration may occur for several disease states, thus facilitating measurable outcomes with a patient centric approach.

Another potential opportunity for outcomes research includes linking EMR data with claims data to build and validate models. If designed correctly, models built using EMR data linked with claims data can be used for continuous quality improvement, forecast logistics, utilization, costs, and cost effectiveness. ${ }^{30}$ The quality and usefulness of a model depends on the quality of the data used to build it. Literature searches and expert opinion have traditionally been used to derive the inputs to simulation models, which are also typically based on assumptions. Large, patient-specific, and comprehensive datasets that are contained in EMR are ideal for generating high quality and reliable models ${ }^{30}$ which can also decrease the use of assumptions increasing model robustness. Utilizing EMR in modeling offers the opportunity to move from hypothetical modeling to actual outcomes analysis. A model developed utilizing EMR data may provide an assessment and forecast of outcomes in the patient population of interest using the clinical characteristics of the actual population.

EMR may also aid in patient identification for study inclusion to clinical trials and registries, as well as improve the efficiency of such prospective studies. Study endpoints can be entered directly into the EMR with reminders for physicians to ensure follow-up and accurate and complete data collection. EMR systems can be designed to improve the efficiency of prospective study data collection through restricted data entry (input ranges and drop-down lists) and forced fields requiring data input before moving to the next data entry field. Increased efficiency can foster comparative effectiveness research to determine which therapies are most successful per treated indication. EMR systems also have value for prospective patient registries.

\section{Challenges of using EMR}

Continuity of care can be an issue if patients are receiving care from several physicians or are being referred for care that is not fully captured in the primary EMR. In a future-oriented context, EHR and personal health records (PHR) will bridge this gap, but neither is widely used (eg, Google Health, Microsoft Health Vault, and various health plan systems, ie, Aetna, Kaiser) (Google Health is a personal health information centralization service or a personal health record services which allows users to volunteer their health records - either manually or by logging into their accounts at partnered health services providers - into the Google Health system, thereby merging potentially separate health records into one centralized Google Health profile. Microsoft HealthVault is a platform to store and maintain health and fitness information. Started in October 2007, the website is accessible at www.healthvault.com and addresses both laymen and healthcare professionals. PHR also confound the dataset by allowing patients to directly enter information which raises data-quality issues.

Medications prescribed or recommended by the physician can be recorded in an EMR; however, these data are even further removed, compared to pharmacy claims data, from actual consumption by the patient. For outcomes research purposes, cost data are not usually part of the EMR, but typically part of the accounting or reimbursement system. Although the capability of cross payer analysis exists, it is quite limited even where EMR exists. While these same challenges are present with paper-based medical charts, EMR offers the opportunity to transcend these obstacles through improved structure and interoperability as well as the potential for data blending of EMR and claims data.

In order to fully reap the benefits of EMR in outcomes research, certain quality standards and a level of consistency in the structure of EMR are needed. Currently, large corporations as well as independent physician organizations are developing EMR systems. Organizations such as CCHIT, the Health Information Technology Standards Panel (HITSP), and the Nationwide Health Information Network (NHIN) are working to harmonize industry-wide standards for EMR and health information technology across the various software suppliers. ${ }^{7}$ These and other industry leading organizations bring standardization in the data nomenclature, attributes, and definitions. The quality of the data entered into the EMR system will drive the quality of the research that can be generated from it. The highest level of quality for EMR would be a fully integrated robust EMR system that would contain data from a variety of clinical service delivery processes, including laboratory, pharmacy, patient registration, radiology, surgical procedures, clinic and inpatient notes, preventive care delivery, emergency department visits and billing information. ${ }^{36}$ Data with this level of integration will create a 


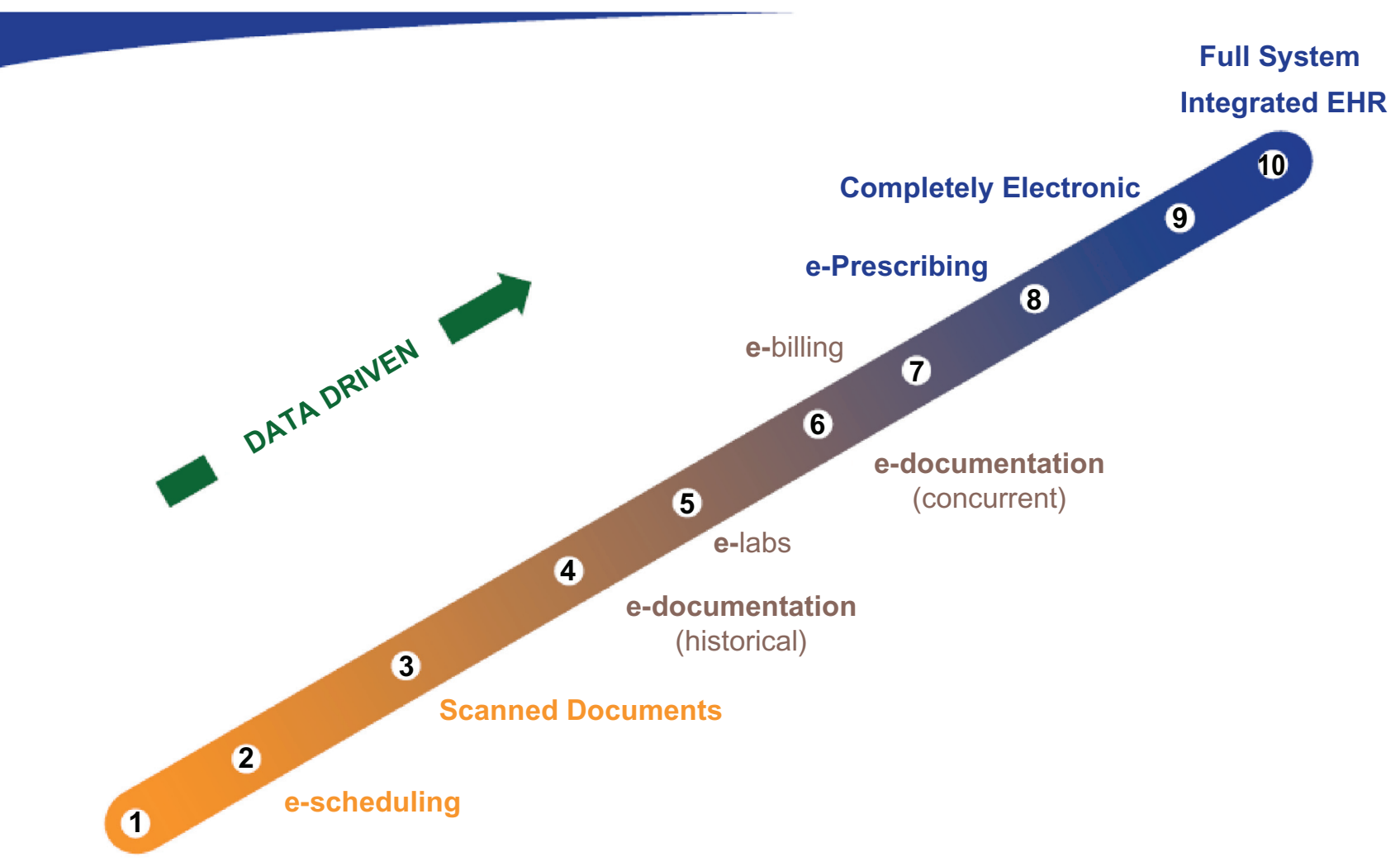

None-Completely Paper

() NOVARTIS

Figure I The continuum of medical record systems - from paper to fully electronic, data driven integration.

timely bidirectional interaction between EMR and outcomes research offering advantages over paper records, enhancing the quality and opportunities for outcomes research, which may ultimately improve patient care. And while these system level attributes may come into convergence, physician level adoption and consistent use of the systems full capability will also play an important role in data quality. While EMR provides value, implementation, even within a practice, can be fragmented. The full scope of the software may or may not be used (such as, eRx, electronic lab capture, data driven documentation). Even in practices where full functional software is utilized, adoption across all practitioners may lead to uneven data acquisition.

Finally, the level of EMR adoption presents special challenges. A recent study on EMR adoption among physicians showed only a $17 \%$ use of either a basic or fully functional system. ${ }^{5}$ Important in this survey is the operational definition of adoption, which the authors defined based on the Institute of Medicine (IOM) framework. ${ }^{37}$ Many practices that have EMR operate at various levels of sophistication (basic vs fully functioning) as well as degree of penetration within the practice. A basic functional EMR is one that includes
1) electronic patient demographics; 2) electronic ordering of prescriptions; 3 ) electronic clinical patient notes; and 4) electronic access to test results. The fully functioning EMR includes all the points listed above including 1) electronic ordering of laboratory and radiology tests; 2) prescriptions and orders sent electronically; 3 ) electronic images returned; and 4) clinical decision making support. ${ }^{5}$ This variation in adoption and actual full use of the particular system may not facilitate consistent, accurate, and complete datasets that one would expect out of an electronic system.

\section{Discussion}

\section{The future of EMR}

\section{in outcomes research}

Often referred to as the Holy Grail, the ability to link EMR data to billing claims data, and potentially even patient survey data, will change the paradigm of outcomes research. ${ }^{52}$ Researchers will have the ability to fully measure patient outcomes by having access to both physician prescribing patterns, and patient utilization patterns, as well as clinical, resource utilization and potentially patient-reported outcomes. Recognizing 
this benefit, innovative organizations are increasing system capabilities to achieve a full integration of data with labs, pharmacy, and medical claims. As the adoption of EMR continues to progress, it can be expected that EMR will play a key role in the future of outcomes research. Moreover, the quality of the research conducted and evidence generated may reach a point where it becomes standard of care to assess outcomes for all disease conditions utilizing integrated data systems.

Additionally, EMRs can provide physician practices with involvement in multi-site, multi-organizational research activities - creating the opportunity to become part of research consortiums not unlike ones that exist for health plans. The HMO Research Network, a consortium of 15 plans, builds on the research resources of each plan providing information that can be translated into clinical practice. Many of the plans also have a network of providers who have EMR ${ }^{38}$ The creation of larger, more integrated research consortiums will improve the quality of data available for outcomes research. The electronic Primary Care Research Network (ePCRN) utilizes EMR technology to enable practices to create disease registries and report quality indicators, and to better communicate and coordinate activities among practices. ${ }^{39}$ Physician practices can form practice-based research networks providing a diverse patient population from which to perform health economic and outcomes research. ${ }^{40}$ As noted earlier, physicians and agencies have used EMRs to track outcomes such as a diabetes population in the aggregate. ${ }^{41}$

As the trend among organizations to adopt EMR technology increases, outcomes research utilizing EMR technology will follow in its footsteps. Individuals embracing the concept of outcomes research utilizing EMR technology will be at the forefront of defining the value of healthcare delivery. Ultimately, providers, employers, payers, and other healthcare decision makers will benefit from EMR technology for decisions on the use of healthcare technologies.

\section{Disclosures}

The authors declare no conflicts of interest.

\section{References}

1. Sheldon I. Dorenfest and Associates. Healthcare information technology spending is growing rapidly. Chicago, IL; 2004.

2. Safran C, Bloomrosen M, Hammond WE, et al. Toward a national framework for the secondary use of health data: an American Medical Informatics Association White Paper. J Am Med Inform Assoc. 2007;14:1-9.

3. US Department of Veterans Affairs. VistA Monograph 2005-2006. www.va.gov/vista_monograph/docs/vista-monograph2005_06.pdf. Accessed February 20, 2008.

4. Jha AK, Ferris TG, Donelan K, DesRoches C, et al. How common are electronic health records in the United States? A summary of the evidence. Health Aff. 2006;25:w496-w507.
5. DesRoches CM, Campbell EG, Rao SR, Donelan K, et al. Electronic health records in ambulatory care- a national survey of physicians. N Engl J Med. 2008;359:50-60.

6. General Electric Healthcare. Centricity Electronic Medical Record. www.gehealthcare.com/usen/lit/products/centricity_practice. Accessed July 3, 2008.

7. HHS announces project to help 3.6 million consumers reap benefits of electronic health records. http://www.hhs.gov/press/2007pres/10/ pr20071030a.html. Accessed January 10, 2008.

8. HIMSS - e-prescribing article under website. http://www.himss.org/ ASP/topics_eprescribing.asp

9. Davis K, Collins CR, Kriss JL. An analysis of leading Congressional health care bills, 2005-2007: Part 2, quality and efficiency. The Commonwealth Fund; 2007.

10. Certification Commission for Healthcare Information Technology. www.cchit.org. Accessed February 8, 2010.

11. Bridges to Excellence offers bonuses for the use of CCHIT Certified EHRs. www.bridgestoexcellence.org. Accessed February 8, 2010.

12. Ober S, Craven G; Craven and Ober Policy Strategists, LLC. American Recovery and Reinvestment Act of 2009 health information technology provisions: a "HIT" or miss? J Infus Nurs. 2009;32(3):122-123.

13. Schoeffler LE. The American Recovery and Reinvestment Act of 2009. J Okla State Med Assoc. 2009;102(3):80-81.

14. American Medical Association. H-315.973 Guiding principles for the collection, use, and warehousing of electronic medical records and claims data. www.ama-assn.org/apps/pf_new/pf_online. Accessed: February 1, 2008.

15. Institute of Medicine, Committee on Data Standards for Patient Safety: Board of Health Care Services. Key capabilities of an electronic health record system. National Academies Press: Washington, DC; 2003. www.nap.edu. Accessed February 8, 2010.

16. AHRQ Practice-Based Research Networks (PBRNs). Fact Sheet, June 2001 (revised May 2006). AHRQ Publication No. 01-P020. Agency for Healthcare Research and Quality, Rockville, MD. http:// www.ahrq.gov/research/pbrn/pbrnfact.htm. Accessed February 8, 2010 .

17. Medical Records Institute. New survey addresses relationship of EMRs to malpractice risk. http://www.medrecinst.com/press $\% 20$ release $\% 20 \mathrm{r}$ esidents\%20survey.pdf Accessed August 7, 2007.

18. Partners Healthcare. Using payment incentives to improve care delivery. 2007. Boston, MA; 2007.

19. Automated detection and reporting of notifiable diseases using electronic medical records versus passive surveillance - Massachusetts, June 2006-July 2007. MMWR Morb Mortal Wkly Rep. 2008;57:373-376.

20. Hillestad R, Bigelow J, Bower A, et al. Can electronic medical record systems transform health care? Potential health benefits, savings and costs. Health Aff. 2005;25:1103-1117.

21. Miller RH, Sim I. Physicians' use of electronic medical records: barriers and solutions. Health Aff. 2004;23(2):116-126.

22. Outcomes Research. Fact Sheet. AHRQ Publication No.00-P011, March 2000. Agency for Healthcare Research and Quality, Rockville, MD. http://www.ahrq.gov/clinic/outfact.htm. Accessed February 8, 2010.

23. Centers for Medicare and Medicaid Services (CMS) (2007) Pilot Testing of Initial Electronic Prescribing Standards - Cooperative Agreements Required Under Section 1860D-(4) (e) of the Social Security Act as Amended by the Medicare Prescription Drug, Improvement, and Modernization Action (MMA) of 2003. Report to Congress.

24. Liang L. The gap between evidence and practice. Health Aff. 2007;26: w119-w121.

25. Bates, DW, Evans, RS, Murff, H, et al. Detecting adverse events using information technology. J Am Med Inform Assoc. 2003;10:115-128.

26. Green CJ, Fortin P, Maclure M, et al. Information system support as a critical success factor for chronic disease management: Necessary but not sufficient. Int J Med Inform. 2006;75:818-828.

27. Owen RR, Carol R, Thrush MA et al. Use of electronic medical record data for quality improvement in schizophrenia treatment $J \mathrm{Am} \mathrm{Med}$ Inform Assoc. 2004;11:351-357. 
28. http://archive.healthmgttech.com/archives/1104/1104beyond_clinical. $\mathrm{htm}$. Accessed 8 February 2010.

29. Benin AL, Vitkauskas G, Thornquist E, Shiffman AR, et al. Improving diagnostic testing and reducing overuse of antibiotics for children with pharyngitis: a useful role for the electronic medical record. Pediatric Infect Dis J. 2003;22:1043-1047.

30. Eddy DM. Linking electronic medical records to large-scale simulation models: can we put rapid learning on turbo? Health Aff. 2007;26: w125-w136.

31. drgreiver.blogspot.com/2008/06/research-and-quality-improvement. html. Accessed 8 February 2010.

32. Gilmore J, Feinberg B, Gondesen T, et al. Hematologic and transfusion outcomes following implementation of the erythropoiesis-stimulating agent (ESA) National Coverage Determination (NCD) in Medicare cancer patients receiving chemotherapy [poster]. Presented at: The 2008 American Society of Clinical Oncology Annual Meeting; May 30 - June 3, 2008; Chicago, Illinois, USA.

33. Safran C, Rind DM, Davis RB, et al. Guidelines for management of HIV infection with computer-based patient's record. Lancet. 1995; 346:341-346.

34. International Society for Pharmacoeconomics and Outcomes Research (ISPOR). Pharmacoeconomics: Identifying the Issues, Advisory Panel Reports; 1998, http://www.ispor.org/workpaper/adpanel/index_.asp. Accessed 8 February 2010.

35. Stewart WF, Shah NR, Selna MJ, et al. Bridging the inferential gap the electronic health record and clinical evidence. Health Aff. 2007;26: w181-w191.

36. Agency for Healthcare Research and Quality (AHRQ). AHRQ National Resource Center for Health Information Technology: Electronic Medical/ Health Records. http://healthit.ahrq.gov. Accessed February 1, 2008.

37. International Society for Pharmacoeconomics and Outcomes Research (ISPOR). PRO Task Force: Changing Mode of Administration of Instruments/ePRO; 2008. http://www.ispor.org/taskforces/ePROTF. asp. Accessed 8 February 2010.

38. Butcher L. Health plans come together for better outcomes research. Managed Care. 2008;17:28-31.

39. http://www.mafp.org/default.asp. Accessed 8 February 2010.

40. AHRQ Support for Primary Care Practice-Based Research Networks (PBRNs). http://www.ahrq.gov/research/pbrn/pbrnfact.htm. Accessed Feb 18, 2010.

41. Agency for Healthcare Research and Quality (AHRQ) Grant: Santa Cruz County, CA Diabetes Mellitus Registry (DMR), 2004-2007.

42. Miller RH, West CE. The value of electronic health record in community health centers: policy implications. Health Aff. 2007;26:206-214.
43. Baron RJ. Quality improvement with an electronic health record: achievable, but not automatic. Ann Intern Med. 2007;147:549-552.

44. Crosson JC, Obman-Strickland PA, Hahn KA, DiCicci-Bloom B, et al. Electronic medical records and diabetes quality of care: results from a sample of family medicine practices. Ann Fam Med. 2007;5: 209-215.

45. Ornstein SM, Jenkins RG, MacFarlane L, et al. Electronic medical records as a tool for quality improvement in ambulatory practice: theory and a case study. Top Health Inf Manage. 1998;19:35-43.

46. Henry SB, Morris JA, Holzemer WL. Using structured text and templates to capture health status in the electronic health record. Jt Comm J Qual Improv. 1997;23:667-677.

47. Wuerdeman L, Volk L, Pizziferri L, Tsurikova R, et al. How accurate is information that patients contribute to their electronic health record? AMIA Annu Symp Proc. 2005;834-838.

48. Staroselky M, Volk LA, Tsurikova R, Pizziferri L, et al. Improving electronic health record (EHR) accuracy and increasing compliance with health maintenance clinical guidelines through patient access and input. Int J Med Inform. 2006;75:693-700.

49. Staroselky M, Volk LA, Tsurikova R, Newmark LP, et al. An effort to improve electronic health record medication list accuracy between visits: patients' and physicians' response. Int J Med Inform. 2008:77:153-160.

50. Pakhomov S, Weston SA, Jacobsen SJ, Chute CG, et al. Electronic medical records for clinical research: Application to the identification of heart failure. Am J Manag Care. 2007;13:281-288.

51. Diero L, Rotich JK, Bii J, Mamlin BW, et al. A computer-based medical record system and personal digital assistants to assess and follow patients with respiratory tract infections visiting a rural Kenyan health centre. BMC Med Inform Decis Mak. 2006;6:21-50.

52. Hogan RW, Mattison J. Toward the electronic medical record: in pursuit of an electronic Holy Grail in a cost conscious era. HMO Pract. 1993;7:54-55.

53. Shah NR, Hirsch AG, Zacker C, et al. Predictors of first-fill adherence for patients with hypertension. Am J Hypertens. 2009;22:392-396.

54. Garg AX, Adhikari NK, McDonald H, et al. Effects of computerized clinical decision support systems on practitioner performance and patient outcomes: a systematic review. JAMA. 2005;293: 1223-1238.

55. Pace WD, Cifuentes M, Valuck RJ, Staton EW, Brandt EC, West DR. An electronic practice-based network for observational comparative effectiveness research. Ann Intern Med. 2009;151:338-340.

56. Chaudhry B, Wang J, Wu S, et al. Systematic review: impact of health information technology on quality, efficiency, and costs of medical care. Ann Intern Med. 2006;144:742-752.
Patient Related Outcome Measures

\section{Publish your work in this journal}

Patient Related Outcome Measures is an international, peer-reviewed, open access journal focusing on treatment outcomes specifically relevant to patients. All aspects of patient care are addressed within the journal and practitioners from all disciplines are invited to submit their work as well as healthcare researchers and patient support groups. Areas covered will

\section{Dovepress}

include: Quality of life scores; Patient satisfaction audits; Treatment outcomes that focus on the patient; Research into improving patient outcomes; Hypotheses of interventions to improve outcomes; Short communications that illustrate improved outcomes; Case reports or series that show an improved patient experience; Patient journey descriptions or research. 